\title{
Analisis Pendapatan Usaha Kudapan di Desa Humusu Wini Kecamatan Insana Utara Kabupaten Timor Tengah Utara (Study Kasus Warung Restu Bunda)
}

\author{
Ivin Ashari Ramadhan Pabate ${ }^{a}$, Yosefina Marice Fallo \\ ${ }^{a}$ Fakultas Pertanian, Universitas Timor, TTU-NTT, Indonesia. Email: asharipabate@gmail.com \\ ${ }^{b}$ Fakultas Pertanian, Universitas Timor, TTU-NTT, Indonesia. Email: yosefinamaricefallo@ gmail.com
}

\section{Article Info}

\section{Article history:}

Received 12 Februari 2019

Received in revised form 5 Maret 2019

Accepted 14 April 2019

DOI:

https://doi.org/10.32938/ag.v4i2.598

Keywords:

Warung

Kudapan Kuliner
Abstrak

Penelitian ini bertujuan untuk : (i) mengetahui besarnya biaya operasional (ii) penerimaan dan (iii) pendapatan usaha gorengan Warun Restu Bunda di Desa Humusu Wini Kecamatan Insana Utara Kabupaten Timor Tengah Utara. Penelitian ini dilaksanakan di Desa Humusu Wini Kecamatan Insana Utara Kabupaten Timor Tengah Utara pada bulan maret 2017. Metode yang digunakan dalam penelitian ini adalah metode deskriptif dengan pendekatan kuantitatif. Hasil penelitian menunjukkan penerimaan usaha kuliner gorengan sebesar Rp 15.780.000 dari total biaya sebesar Rp 11.169.318. Sehingga pendapatan bersih per hari sebesar Rp 4.610.681. dari hasil perhitungan dapat diketahui selisi $\mathrm{R} / \mathrm{C}$ rasio sebesar $(1,41)$ usaha menguntungkan.

\section{Pendahuluan}

Sektor kuliner merupakan salah satu sektor penting dalam proses penyerapan hasil pertanian. Sektor kuliner dipenuhi dengan berbagai varian makanan, mulai dari kudapan, kue , sampai makanan khas nusantara Pengusaha kuliner berinisiatif untuk menyajikan makanan yang berbeda . Hal tersebut dilakukan untuk menarik perhatian konsumen terhadap jenis makanan yang disajikan. Semua makanan itu dijual dengan harga yang berbeda-beda, disesuaikan dengan bahan baku makanan yang digunakan. Sebagian besar orang memilih makanan yang mengenyangkan dengan harga yang terbilang murah. Salah satu makanan yang mudah dijangkau dengan harga yang relatif murah adalah "Gorengan", dengan bahan dasar tepung terigu yang cukup mengandung karbohidrat sebagai alternatif asupan kalori dan proses penyajiannya yang terbilang cepat.

Peningkatan jumlah penduduk dan perpindahan dari satu daerah ke daerah lain menciptakan permintaan baru terhadap satu jenis barang atau jasa. Permintaan terhadap barang dan jasa yang baru, menciptakan peluang usaha baru.

"Gorengan" merupakan salah satu kudapan khas nusantara, teknik menggoreng dalam minyak berjumlah banyak (deep frying), sudah digunakan sejak tahun 1200 SM di Mesir (Toussaint-Samat, 2009). Gorengan biasanya dinikmati dengan minuman dan pada waktu senggang. "Gorengan" merupakan salah satu barang komplementer untuk kopi dan teh. Meningkatnya konsumsi kopi dan teh, meningkatkan permintaan terhadap gorengan (Sukirno, 2002).

Di Indonesia, teknik menggoreng dan jenis makanan yang digoreng dibawa pendatang dari Cina,yang berjasa besar bagi khazanah kuliner Nusantara. Etnis tionghoa memperkenalkan maknn seperti mi, bakso, atau tahu, dan juga teknik - teknik masak yang sebelumnya tidak dikenal masyarakat Nusantara (Bromokusumo, 2013).

Desa Humusu Wini merupakan salah satu desa perbatasan NKRIRDTL. Penjual gorengan di desa Humusu terdapat satu pengusaha penjualan gorengan. Pengelola memberi nama usahanya dengan sebutan "Warung Restu Bunda". Usaha ini didirikan sejak Desember 2015 atau kurang lebih tiga tahun. Tantangan dalam menjalani usaha gorengan yaitu membutuhkan beberapa macam bahan baku sayuran seperti kol, wortel dan buncis, juga beberapa bumbu lainnya, sedangkan pasar harian tidak beroperasi di Desa Humusu Wini.

\section{Metode}

Penelitian ini dilaksanakan di Desa Humusu Wini - Kecamatan Insana Utara, Kabupaten Timor Tengah Utara selama kurang lebih dua minggu, dimulai dari tahap awal survei hingga tahap pengolahan data. Waktu pelaksanaan penelitian pada bulan maret 2018. Jenis penelitian yang digunakan dalam penelitian ini adalah metode deskriptif dengan pendekatan kuantitatif, yang bertujuan untuk menggambarkan keadaan atau situasi yang sedang berjalan pada saat dilakukan penelitian. Menurut Soemantri (2010), metode penelitian deskriptif merupakan metode penelitian yang tujuannya menjelaskan peristiwa yang sedang berlangsung. Metode penelitian kuantitatif merupakan salah satu jenis penelitian yang terperinci, sistematis, dan terstruktur. Metode penelitian ini memfokuskan pada penggunaan angka seperti tingkat biaya operasional hingga analisis pendapatan usaha gorengan.

Penerimaan merupakan hasil kali antara jumlah produksi yang diperoleh dengan harga jual Soekartawi (1995). Rumus untuk menghitung besarnya penerimaan usaha gorengan adalah :

dimana: $\begin{array}{ll}\operatorname{Tr}=\mathbf{y} \cdot \mathbf{P y} & \\ \operatorname{Tr} & =\text { Total penerimaan dalam suatu usaha } \\ \mathrm{Y} & =\text { Produksi yang diperoleh dari suatu usaha } \\ \text { Py } & =\text { Harga (y) dalam suatu usaha }\end{array}$

Pendapatan merupakan jumlah seluruh produksi berupa barang atau jasa yang dihasilkan. Pendapatan usaha gorengan diperoleh dari selisih antara penerimaan dengan semua biaya (Soekartawi, 1995). Rumus untuk menghitung besarnya pendapatan bersih adalah :

$$
\begin{array}{lll} 
& \text { I } & =\mathbf{T r}-\mathbf{T c} \\
\operatorname{dimana}: & \mathrm{I} & =\text { Pendapatan warung gorengan } \\
& \mathrm{Tr} & =\text { Total penjualan }
\end{array}
$$

\section{Hasil dan Pembahasan}

\subsection{Karakteristik Pengusaha Warung Gorengan Restu Bunda}

Kewirausahaan merupakan salah satu pilihan karir yang berkaitan dangan karakteristik seorang pengusaha, karena sumber daya manusia (SDM) adalah modal awal kewirausahaan baik secara personal maupun korporasi.Responden dalam penelitian adalah pengusaha kuliner, bernama Muhamad Taufiq. Bermodalkan pengalaman kerja di bidang kuliner semenjak bekerja di daerah asalnya, pengusaha ini datang dan menjalani usaha yang sama di Desa Humusu Wini dengan nama usaha "Warung Restu Bunda". Penelitian ini dilakukan dengan tujuan untuk mengetahui secara jelas dan akurat mengenai gambaran responden sebagai objek penelitian ini. Gambaran umum responden dalam penelitian ini dapat dijelaskan sebagai berikut :

\section{Umur Responden}

Salah satu faktor yang mempunyai pengaruh terhadap produktivitas pengusaha adalah faktor usia. Badan Pusat Statistik (BPS) mendefinisikan kelompok usia produktif adalah mereka yang berada dalam rentang usia 15 sampai dengan 64 tahun. Berdasarkan data sensus penduduk tahun 2010 jumlah penduduk Indonesia yang masuk dalam kelompok usia produktif adalah sekitar 157 juta orang (BPS, 2016). Data hasil wawancara dalam penelitian in menunjukkan bahwa umur responden adalah

35 Tahun adalah usia yang tergolong produktif

\section{Pendidikan}

Pendidikan dapat menjadi salah satu faktor pembentukan pola pikir seorang dalam mengelola usaha serta menjadi suatu indikator keberhasilan yang sangat penting dalam pengembangan sumber daya manusia. Semakin tinggi tingkat pendidikan maka produktivitas kerja semakin meningkat, karena pendidikan mempunyai pengaruh besar dalam menentukan berbagai kebutuhan dalam meningkatkan pendapatannya. Tingkat pendidikan yang rendah sanga berpengaruh pada kecakapan dan wawasan berpikir yang akhirnya mempengaruhi pendapatan usaha gorengan yang di bangunnya. Berdasarkan hasil penelitian, pendidikan pengusaha gorengan Warung Restu Bunda di Desa Humusu Wini hanya menyelesaikan pendidikan di bangku SLTP.

\section{Pengalaman Kerja}

Pengalaman merupakan salah satu faktor yang menentukan keberhasilan seseorang dalam menjalankan usaha. Semakin lama seseorang menjalankan suatu usaha maka dia akan semakin memiliki kemampuan mengelola faktor produksi sehingga dapat mencapai keuntungan maksimal. Sebelum mulai merintis usahanya di Desa Humusu Wini, Pengelola sebelumnya telah mahir dalam mengolah bahan makanan semenjak bekerja di warung milik Keluarga empat tahun lamanya.

\subsection{Analisis Pendapatan Warung Gorengan Restu Bunda.}

\section{Menjaga kualitas Olahan}

Beberapa hal yang dapat dilakukan untuk menjaga eksistensi bisnis usaha antara lain harga, menjaga kualitas produk, product knowledge dan surve berkelanjutan (Kotler, 2011). Selain dengan memperhatikan kesegaran bahan baku, takaran bumbu dan bahan tambahan lainnya, perlu juga diperhatikan penggantian terhadap minyak goreng yang digunakan untuk memproduksi aneka gorengan. Dalam bisnis kuliner, kualitas produk merupakan faktor yang harus diutamakan. Pengelola harus terus memastikan bahwa kualitas makanan 
yang dijual kepada konsumen selalu dalam kondisi yang baik. Kualitas produk yang buruk bisa menyebabkan hilangnya kesetiaan pelanggan dan beralih ke kompetitor. Pada dasarnya, konsumen berkecenderungan mendapatkan jumlah makan sebanyak-banyaknya dengan harga serendah mungkin. Hal ini yang seringkali membuat sebagian pengusaha gorengan lupa menjaga kualitas olahan mereka dengan menggunakan minyak bekas pakai yang seharusnya tidak digunakan lagi untuk menggoreng. Minyak tersebut sering disebut dengan minyak jelantah. Minyak jelantah membuat cita rasa gorengan menjadi kurang enak karena sudah mengalami pengulangan penggorengan beberapa kali.

Pengelola selalu menjaga kualitas olahan gorengan karena hasil olahan gorengan bukan hanya untuk dipasarkan namun juga dikonsumsi anggota keluarga sendiri. Kepuasan konsumen tetap diutamakan, salah satunya menjaga kebersihan dan kesehatan hasil olahan gorengan dengan mengganti minyak goreng yang digunakan secara berkala atau ketika mulai terlihat keruh, tepatnya setelah tiga kali penggorengan demi menjaga cita rasa dan kualitas olahan gorengan.

\section{Pengeluaran rutin harian}

\section{Tabel 1. Pengeluaran Rutin Harian}

\begin{tabular}{|c|c|c|}
\hline No & Jenis Gorengan & $\begin{array}{c}\text { Rata }^{2} \text { PengeluaranPerhari } \\
(\mathbf{R p})\end{array}$ \\
\hline$\overline{1}$ & Bakwan & 40.871 \\
\hline 2 & Tahu isi & 88.466 \\
\hline 3 & Pisang Goreng & 81.600 \\
\hline \multirow[t]{2}{*}{4} & Tempe Goreng & 77.600 \\
\hline & Bahan bakar dan sarana lain & \\
\hline 5 & Minyak Tanah & 10.714 \\
\hline 6 & Plastik Pembungkus & 2.142 \\
\hline \multirow[t]{2}{*}{7} & Tissu & 2.285 \\
\hline & Pelengkap Gorengan & \\
\hline 8 & Cabe & 3.571 \\
\hline 9 & Kecap dan Saus & 9.285 \\
\hline \multirow[t]{2}{*}{10} & Minyak goreng, susut ( $\pm 1,3 \mathrm{~L} / \mathrm{hari})$ & 18,850 \\
\hline & Total & 335.384 \\
\hline
\end{tabular}

\section{Sumber data primer diolah (2018)}

Pengeluaran rutin dapat dijadikan sebagai acuan dalam menentukan penerimaan mingguan dan bulanan. Dikarenakan,usaha Warung Gorengan Restu Bunda termasuk dalam usaha yang berkelanjutan juga dengan jangka waktu yang panjang. Berdasarkan penelitian (28 Mei - 4 Juni 2018) rata -rata pengeluaran rutin sebesar Rp 335.384 dengan rincian bahan olahan bakwan sebesar Rp40.871 per hari, tahu isi sebesar Rp 88.466 per hari , pisang goreng sebesar Rp 81.600 dan Tempe goreng sebesar Rp 77.600, bahan bakar, sarana lain dan pelengkap sebesar Rp 46.847 per hari.

\section{Biaya Variabel}

Menurut (Mulyadi, 2009), biaya variabel adalah biaya yang jumlah totalnya sebanding dengan perubahan volume kegiatan. Biaya variabel dalam penelitian adalah biaya operasional secara langsung, berupa pengeluaran rutin bahan baku untuk keempat jenis olahan gorengan.

\section{Biaya Tetap}

Menurut (Mulyadi, 2005), biaya tetap adalah biaya yang jumlahnya tetap konstan, tidak dipengaruhi perubahan volume kegiatan atau aktivitas sampai tingkat kegiatan tertentu. Biaya tetap dalam penelitian ini adalah penyusutan peralatan usaha gorengan. Berbagai macam peralatan telah di persiapkan pengelola untuk memperlancar proses olahan aneka gorengan yang berkualitas. Usaha aneka gorengan membutuhkan peralatan seperti wajan, wadah, kompor, pengangkat makanan, dan berbagai peralatan penunjang lainnya. Beberapa peralatan juga telah di siapkan sebelum memulai usaha tanpa perlu membelanjakannya lagi.

\section{Biaya bersama (Joint Cost)}

Biaya bersama (joint Cost) adalah biaya-biaya yang dikeluarkan sejak pertama kali bahan baku diolah sampai saat berbagai macam produk dapat dipisahkan, join cost dalam penelitian ini adalah biaya penyusutan investasi peralatan, penggunaan bahan baku gorengan dalam presentase terbesar, serta pajak usaha yang dibelanjakan selama sebulan yang dibagi dengan keempat jenis olahan gorengan. Berdasarkan hasil perhitungan diperoleh join cost untuk penyusutan alat sebesar Rp 206.121,5 dari total keseluruhan biaya penyusutan sebesar Rp 824.486. Total keseluruhan biaya penyusutan dibagi empat, karena total biaya penyusutan digunakan untuk keempat jenis olahan gorengan, yaitu : bakwan, tahu isi, tempe goreng dan pisang goreng, joint cost untuk penggunaan bahan baku dan sarana lain (tepung terigu, minyak goreng dan minyak tanah) sebesar Rp 872.500 dari total presentase penggunaan bersama bahan baku dan sarana lain sebesar 3.490.000 dibagi dengan keempat jenis olahan gorengan dan pajak usaha sebesar Rp 8.333 dari total pajak usaha bulanan sebesar Rp 33.300 Biaya abonemen tagihan listrik sebesar Rp 62.500 dari biaya langganan listrik per bulan (dalam penelitian) sebesar Rp 250.000

\section{Penerimaan Usaha Gorengan}

Penerimaan merupakan perkalian antara produksi hasil olahan gorengan dengan harga jual olahan gorengan per buah. Berdasarkan hasil perhitungan rata-rata produksi olahan gorengan sebanyak 487 buah dengan rata-rata produksi olahan gorengan yang terjual sebanyak 478 buah per hari dengan rincian olahan (bakwan 160 buah, tahu isi 96 buah, tempe goreng 84 buah, dan pisang goreng 138 buah).

Rata-rata penerimaan hasil olahan aneka gorengan yang terjual tiap harinya sebesar Rp 526.000 dengan rincian olahan (bakwan $\mathrm{Rp} 160.000$, tahu isi $\mathrm{Rp}$ 144.000, tempe goreng $\mathrm{Rp}$ 84.000, dan pisang goreng $\mathrm{Rp}$ 138.000). Sehingga peneriman dari usaha Warung Gorengan Restu Bunda dalam satu minggu sebesar Rp 3.682.000, dan penerimaan dalam satu bulan sebesar Rp 15.780.000. Lebih jelasnya dapat di lihat dalam tabel rata-rata penerimaan rutin harian hingga bulanan pada rincian tabel $2-4$ berikut :

\section{Tabel 2. Uraian Penerimaan Harian Warung Gorengan Restu Bunda}

\begin{tabular}{lccc}
\hline Jenis Gorengan & Rata-rata terjual (buah) & Harga(Rp) & Penerimaan(Rp) \\
\hline Bakwan & 160 & 1000 & 160000 \\
Tahu Isi & 96 & 1500 & 144000 \\
Tempe Goreng & 84 & 1000 & 84000 \\
Pisang Goreng & 138 & 1000 & 138000 \\
\hline Total & 478 & & 526000 \\
\hline
\end{tabular}

\section{Sumber data primer diolah (2018)}

Berdasarkan Tabel 2, dinyatakan bahwa penerimaan harian bakwan sebesar Rp 160.000 dengan total penjualan sebanyak 160 buah, lebih besar dibandingkan penerimaan tahu isi, tempe goreng, dan pisang goreng. Penerimaan tahu isi sebesar Rp 144.000 dengan penjualan sebanyak 96 buah, tempe goreng 84 buah, dan pisang goreng 138 buah. Berdasarkan tabel juga dapat di lihat penerimaan jenis "gorengan" yang diteliti.

Tabel 3. Uraian Penerimaan Per Minggu Warung Gorengan Restu Bunda

\begin{tabular}{lccc}
\hline Jenis Gorengan & Rata-rata terjual (buah) & Harga(Rp) & Penerimaan(Rp) \\
\hline Bakwan & 1120 & 1000 & 1120000 \\
Tahu Isi & 672 & 1500 & 1008000 \\
Tempe Goreng & 588 & 1000 & 588000 \\
Pisang Goreng & 966 & 1000 & 96000 \\
\hline Total & 3346 & & 3682000 \\
\hline
\end{tabular}

Sumber data primer diolah (2018)

Berdasarkan Tabel 3, dinyatakan bahwa penerimaan harian bakwan sebesar Rp 1.120.000 dengan total penjualan sebanyak 1120 buah, lebih besar dibandingkan penerimaan tahu isi, tempe goreng dan pisang goreng Penerimaan tahu isi sebesar Rp 1.008.000 dengan penjualan sebanyak 672 buah, tempe goreng 588 buah dan pisang goreng 966 buah. Berdasarkan tabel juga dapat di lihat penerimaan jenis "gorengan" yang dijual

\section{Tabel 4. Uraian Penerimaan Per Bulan Warung Gorengan Restu Bunda}

\begin{tabular}{lccc}
\hline Jenis Gorengan & Rata-rata terjual (buah) & Harga(Rp) & Penerimaan(Rp) \\
\hline Bakwan & 4800 & 1000 & 4800000 \\
Tahu Isi & 2880 & 1500 & 4320000 \\
Tempe Goreng & 2520 & 1000 & 2520000 \\
Pisang Goreng & 4140 & 1000 & 4140000 \\
Total & 14340 & & 15780000
\end{tabular}

\section{Sumber data primer diolah (2018)}

Berdasarkan Tabel 4, dinyatakan bahwa penerimaan harian bakwan sebesar Rp 4.800.000 dengan total penjualan sebanyak 4800 buah, lebih besar dibandingkan penerimaan tahu isi, tempe goreng dan pisang goreng Penerimaan tahu isi sebesar Rp 4.320.000 dengan penjualan sebanyak 2880 buah, tempe goreng 2520 buah dan pisang goreng 4140 buah.

\section{Pendapatan Usaha Warung Gorengan Restu Bunda}

Pendapatan usaha gorengan Warung Restu Bunda diperoleh dari selisih penerimaan gorengan bakwan, tempe goreng, tahu isi dan pisang goreng dengan biaya yang dikeluarkan yang terdiri dari biaya tetap dan biaya variabel. Berdasarkan hasil perhitungan diperoleh total penerimaan per hari sebesar Rp 526.000 sedangkan total biaya rutin harian sebesar Rp 335.384. Selisih penerimaan harian dan pengeluaran harian dapat diketahui total pendapatan usaha gorengan sebesar Rp 190.616 per hari. Pendapatan per minggu hasil 
olahan gorengan sebesar Rp 1.334.309 dengan total penerimaan per minggu sebesar Rp 3.682.000 dan total biaya operasional per minggu sebesar $\mathrm{Rp}$ 2.347.691. Sedangkan penerimaan per bulan sebesar Rp 15.780.000 dan total biaya operasional per bulan berupa biaya penyusutan , tagihan listrik , pajak dan biaya variabel sebesar Rp 11.169.318,86 , sehingga pendapatan usaha gorengan dalam satu bulan sebesar Rp 4.610.681,14 dengan selisih $\mathrm{R} / \mathrm{C}$ rasio sebesar $(1,41)$ maka usaha gorengan menguntungkan.

\section{Simpulan}

Berdasarkan hasil penelitian dapat disimpulkan bahwa:

Pengelola menyiapkan modal awal dengan menginvestasikannya dalam bentuk etalase warung, persiapan peralatan penggorengan dan modal awa belanja bahan baku usaha produksi Warung Gorengan Restu Bunda.

Penerimaan usaha aneka gorengan sebesar Rp 526.000 per hari dan total biaya pengeluaran rutin belanja bahan baku sebesar Rp 335.384 per hari sebagai biaya variabel sehingga pendapatan bersih per hari sebesar Rp 190.616. Pengelola juga memperoleh total pendapatan bersih dari hasil olahan aneka gorengan (bakwan, tempe goreng, tahu isi dan pisang goreng) sebesar Rp. 4.610.681,14 per bulan dari total penerimaan sebesar Rp 15.780.000 dengan total biaya variabel dan biaya tetapsebesar $\mathrm{Rp} 11.169 .318,86$ per bulan

\section{Pustaka}

Badan Pusat Statistik. 2016. Timor Tengah Utara Dalam Angka.Badan Pusat Statistik. Timor Tengah Utara

Bromokusumo, Aji. 2013. Peranakan Tionghoa dalam Kuliner Nusantara Penerbit Buku Kompas. Jakarta.

Kotler, P., \& Keller, K. (2011). Marketing management 14th edition. Prentice Hall.

Mulyadi. 2005. Akuntansi Biaya, Edisi kelima, Cetakan ketujuh,Yogyakarta : Akademi Manajemen Perusahaan YKPN.

2009. akuntansi Biaya, Edisi 5. Yogyakarta: UPP STIM YKPN

Soekartawi. 1995. AnalisisUsahatani. Universitas Indonesia (UI-Press), Jakarta.

Soemantri, G. R. 2010. Memahami metode kualitatif. Hubs-Asia, 10(1)

Sukirno, S. 2002.Teori Mikro Ekonomi. Cetakan Keempatbelas, Jakarta: PT Raja Grafindo Persada.

Toussaint-Samat, Maguelonne. 2008. A History of Food. Blackwell Publishing (John Willey \& sons, Inc). New Jersey. 